\title{
Exploring quality of care and social inequalities related to type 2 diabetes in Hungary: nationwide representative survey
}

Attila Nagy ${ }^{1}$, Nóra Kovács ${ }^{1}$, Anita Pálinkás ${ }^{1}$, Valéria Sipos ${ }^{1}$, Ferenc Vincze ${ }^{1}$, Gergő Szőllősi ${ }^{1}$, Orsolya Csenteri ${ }^{1}$, Róza Ádány ${ }^{1,2}$, János Sándor ${ }^{1}$

${ }^{1}$ Department of Preventive Medicine, Faculty of Public Health, University of Debrecen, Debrecen, Hungary

${ }^{2}$ MTA-DE Public Health Research Group of the Hungarian Academy of Sciences, Faculty of Public Health, University of Debrecen, Debrecen, Hungary

Running head:

Representative survey on Hungarian diabetes care

Corresponding author:

János Sándor

Department of Preventive Medicine, Faculty of Public Health, University of Debrecen, Debrecen

H-4012 Debrecen, PO Box 2., Hungary

tel: +36209323140

fax: +3652460195

e-mail: sandor.janos@sph.unideb.hu

Keywords: diabetes mellitus; quality of care; social inequalities; process indicators; outcome indicators; diabetes registry 


\begin{abstract}
Aims: The study aimed to launch a T2DM adult cohort that is representative of Hungary through a cross-sectional study, to produce the most important quality indicators for T2DM care, to describe social inequalities, and to estimate the absolute number of T2DM adult patients with uncontrolled HbA1c levels in Hungary.
\end{abstract}

Methods: A representative sample of the Hungarian T2DM adults $(\mathrm{N}=1280)$ was selected in 2016. GPs collected data on socio-demographic status by questionnaire, and on history and laboratory parameters from medical records. The process and outcome indicators used in the international monitoring practice were calculated. The socio-economic status influence was determined by multivariate logistic regression models.

Results: Target achievement was $61.66 \%, 53.48 \%$, and $54.00 \%$ for HbA1c, LDL-C, and blood pressure, respectively, in the studied sample ( $\mathrm{N}=1176)$. In Hungary, 294,534 patients have above target HbA1c value out of 495,801 T2DM adults. The education-dependent positive association with majority of process indicators was not reflected in $\mathrm{HbA1c}$, LDL-C, and blood pressure target achievements. The risk of microvascular complications and requirement of insulin treatment were higher among less educated.

Conclusions: According to our observations, the education-independent target achievement for $\mathrm{HbA1c}$ and LDL-C is similar as, for blood pressure is less effective in Hungary than in Europe.
Abbreviations:
T2DM, type 2 diabetes, T1DM, type 1 diabetes, GPMSSP, General Practitioners' Morbidity Sentinel Stations Program, OR, odds ratio, 95\%CI, 95\% confidence interval, EUBIROD, EUropean Best Information through Regional Outcomes in Diabetes, NIHIFM, National Institute of Health Insurance Fund Management, TC, total cholesterol, TG, triglyceride, LDL- C, LDL-cholesterol, HDL-C, HDL-cholesterol, GP, general practitioner, AMI, acute myocardial infraction, IHD, ischaemic heart disease, BMI, body mass index, HbA1c, haemoglobin A1c, eGFR, estimated glomerular filtration rate 


\section{Introduction}

According to the latest estimations, globally, more than 425 million adults had diabetes in 2017 [1]. T2DM was the $11^{\text {th }}$ leading cause of burden of disease in 2015 [2]. The health and economic burden of T2DM could mainly be described by its complications which are considered largely preventable [3]. Early diagnosis and adequate glycaemic control are essential for preventing and postponing T2DM complications [4,5]. Although, knowledge has been growing on the optimization of T2DM patient care, its translation into daily practice is far from acceptable as it is shown by the recent publications on the therapeutic target achievements [6].

Reflecting the importance of multidisciplinary T2DM care, international organizations have released recommendations for T2DM monitoring systems. Despite their heterogeneity, the main conception and key indicators have significant overlap [6-8]. Minority of the European countries ( 5 of 47 ) has well operating diabetes registry. The lack of reliable monitoring systems is among the factors, which contribute to the weak guideline adherence [9]. Hungary belongs to the group of countries without a well-functioning T2DM care monitoring. However (a) there is a type 1 diabetes (T1DM) monitoring system in Hungary (Hungarian Childhood Diabetes Registry), which covers the entire country with its obligatory reporting system contributing to better-than-European-average long term outcome among children [10,11], and (b) national and international surveys were implemented in Hungary. Recent surveys were not able to produce data representing of the country:

- In the DEPAC multinational survey in 2005, endocrinologists or diabetologists completed questionnaires for the group of T2DM patients who were treated in secondary care settings. The sampling could not cover the T2DM patients who were cared by general practitioners [12].

- A primary health care-based national cross-sectional study was implemented in 2006, which aimed to determine the metabolic disorders' epidemiologic properties. The sampling frame was broader than patients with T2DM [13].

- Another primary care-based survey was performed in 2008, which was focused on T2DM older than 50 years of age $[5,14]$. The results from this survey had been used in the EUropean Best Information through Regional Outcomes in Diabetes (EUBIROD) international collaboration as well [15]. 
The Hungarian Diabetes Association regularly publishes guidelines. Although, these guidelines defines the necessary indicators for quality monitoring according to the international guidelines [16], the proposed indicators are not applied in practice. The only regular, nationwide T2DM care monitoring in Hungary is maintained by the National Institute of Health Insurance Fund Management (NIHIFM). Two process indicators (the proportion of T2DM patients with $\mathrm{HbA} 1 \mathrm{c}$ evaluation and ophthalmological examination in the past 12 months) to evaluate GPs' performance are applied. Their use is not completed with application of outcome indicators. This approach is potentially counter-productive in terms of the quality development because it establishes the interest of service providers in increasing the episode numbers without improving the outcomes [14,17,18].

Altogether, Hungarian T2DM adult care quality has not properly been evaluated yet. The heterogeneity of the performance has not been assessed, even though it is well demonstrated that the poor care quality in certain demographic strata can be responsible for the low effectiveness observed in general population. [19-22] Neither surveys nor continuous monitoring could produce representative data.

According to the Non-communicable Diseases Risk Factor Collaboration's latest estimations, the probability of achieving the target of halting the rise in diabetes by 2025 compared to its 2010-level (among adults 18 years and older), if the post-2000 trends continue, is far from achievable in Hungary[23]. Therefore, this trend has to be targeted by developing/restructuring diabetes care, which is hardly feasible without relying detailed and reliable data from representative monitoring.

The objectives of our study were (1) to launch a national representative T2DM adult cohort through a cross-sectional study, ensuring further possibilities for continuous follow-up, (2) to produce and evaluate in European context the most important process and outcome quality indicators for T2DM care, (3) to describe the social inequalities of these indicators, and (4) to estimate the absolute number of T2DM adult patients with uncontrolled HbA1c levels in Hungary.

\section{Materials and Methods}

\subsection{Setting}


The General Practitioners' Morbidity Sentinel Stations Program (GPMSSP) has collected data on the occurrence and incidence of diseases, which have major public health importance, as a Hungarian surveillance system since 1998. T2DM is among the GPMSSP monitored diseases. It has represented the demographical structure and geographical distribution of the Hungarian population. The design of this programme has been described in detail elsewhere [24].

\subsection{Study design}

A population-based, nationally representative cohort of (above 18 years old) adult T2DM patients was launched in the framework of GPMSSP. A cross-sectional study was performed to start the follow-up.

\subsection{Participants}

Two-stage sampling was performed. The first step was the random selection of 32 out of the total 121 GPMSSP GPs representative of Hungary. The participating GPs prepared their T2DM patient lists, which were used as the sampling frame. These were used in the second stage of sampling with a random selection of 40 patients in each practice, resulting in a total of 1280 subjects. Selected patients had been contacted. Collection of their data had been commenced if they had signed the informed consent form.

\subsection{Data sources}

GPs registered basic information on the participating patients' ages, genders, and levels of education (classified as primary/secondary/tertiary level). The socio-economic status of the patients was approximated by the level of education. The following data on history had been derived from patient records where the general routine of GPs' were used for diagnoses: duration of diabetes, complications/comorbidities (stroke, hypertension, IHD, AMI, retinopathy, nephropathy, and amputation), application of insulin, antihypertensive and antidyslipidemic drugs, date of the last HbA1c check and eye examination, medication related to lipid disorders, hypertension and laboratory investigation. The following laboratory parameters had been retrieved from medical records: fasting blood glucose, HbA1c, BMI, waist circumference, blood pressure, eGFR, total cholesterol (TC), triglyceride (TG), LDLcholesterol (LDL-C), and HDL-cholesterol (HDL-C). The last, a maximum of 12 months prior, registered findings used for analysis, which was derived from routine health check examinations. Recent guidelines were used to dichotomize parameters. The cut-off values 
were as follows: 140/85 $\mathrm{mmHg}$ for blood pressure, $30 \mathrm{~kg} / \mathrm{m}^{2}$ for BMI, 102/88 cm (male/female) for waist circumference, 1/1.3 mmol/l (male/female) for HDL-C, $2.5 \mathrm{mmol} / \mathrm{l}$ for LDL-C, $4.5 \mathrm{mmol} / \mathrm{l}$ for TC, $1.7 \mathrm{mmol} / \mathrm{l}$ for TG and $7.8 \mathrm{mmol} / \mathrm{l}$ for fasting blood glucose [25]. For HbA1c, we used individualized values based on recent target range recommendations [26]. Data collection was performed in 2016.

\subsection{Statistical analysis}

Descriptive statistics were created on patient characteristics, on the following process quality indicators: proportions of patients who received an annual check for HbA1c, eGFR and lipid (TC, LDL-C, HDL-C, TG) status, ophthalmological and physical examination (blood pressure, BMI and waist circumference measurements), and on the following outcome indicators: whose hypertension and dyslipidaemia had been treated, had controlled fasting blood glucose, HbA1c, TC, TG, LDL-C, and HDL-C levels, and had controlled BMI, waist circumference, and blood pressure. Proportions of patients with diagnosed complications (stroke, hypertension, IHD, AMI, retinopathy, nephropathy, and amputation) and with launched insulin therapy have been also computed.

Proportions were computed with $95 \%$ confidence intervals (95\%CI). All the descriptive indicators have been computed for each levels of education (primary,secondary,tertiary respectively) also. The difference between education specific indicators has been tested by chi-squared test.

The observed gender- and age-specific (by 18-44, 45-64, and above 65 years-of-age groups) proportions of the HbA1c target achievement, the GPMSSP-derived corresponding T2DM prevalence rates, and the population composition of the whole country were used to estimate the percentage and number of T2DM patients who reached an HbA1c target in Hungary. Weights were applied to correct for the unequal probability of selection and for nonresponse as well as to perform post-stratification by age and gender in the survey. The survey analysis module of Stata was used to calculate the $95 \%$ confidence intervals of the prevalence estimates after considering the sampling design [27].

Multivariate logistic regression modelling was used to investigate the influence of sociodemographic and clinical factors on achievement of quality indicators. The effects of the age, gender, level of education, duration of T2DM, requirement of insulin treatment and comorbidities on reaching the target HbA1c, fasting blood glucose, BMI, waist circumference, blood pressure, TC, TG, LDL-C, and HDL-C and undergoing an annual HbA1c check, ophthalmological examination, BMI and waist circumference measurements, 
and assessment of TC, TG, LDL-C, and HDL-C concentrations, and implementation of required antihypertensive and anti-dyslipidaemic treatments were quantified.

The age, gender, level of education, and duration of T2DM were controlled for in the statistical models where comorbidities, complications, and requirement of insulin treatment were the dependent variables. The results were described by the odds ratios (OR) and their 95\% confidence intervals. Statistical analysis was performed by Stata (version 10) [28].

\section{Results}

The study response rate was $91.87 \%$. The completed database consisted of 1176 participants. (Figure 1)

\subsection{Sample characteristics}

The female/male ratio was $1.22\left(\mathrm{n}_{\text {female }}=647, \mathrm{n}_{\text {male }}=529\right)$. The mean $( \pm \mathrm{SD})$ age of diabetes patients and average duration of diabetes were $66.52( \pm 11.12)$ and $9.76( \pm 6.73)$ years in the sample. The distribution of patients with education levels was followings: $39.63 \%$ with primary education, $47.28 \%$ with secondary education and $13.10 \%$ with tertiary education. Insulin therapy, antihypertensive and anti-dyslipidaemic medication were applied in 236 (20.05\%), $1020(86.66 \%)$, and $676(57.43 \%)$ of patients, respectively.

The highest prevalence among comorbidities was observed for hypertension (87.24\%), while the lowest prevalence was observed for amputation (0.77\%). Stroke (8.16\%) and AMI $(6.38 \%)$ were associated with similar proportions, while IHD (33.16\%) had a higher proportion. Retinopathy and nephropathy affected 180 (15.31\%) and 183 (15.56\%) participants. (Appendix 3)

\subsection{Process and outcome indicators}

Annual HbA1c check and ophthalmological examination were attended by 1020 and 755 patients, the attendance rates and 95\%CIs were 86.73\% [84.80-88.67\%] and 64.20\% [61.46$66.94 \%]$, respectively. The proportion of patients who participated in physical examination and laboratory investigation varied from 57.4 to $100 \%$. The assessment of the LDL-C, eGFR, and HDL-C statuses was implemented in less than $80 \%$. (Table 1, Appendix) 
The mean HbA1c level was $7.06 \%( \pm 1.35 \%)$, which ranged from 4.40 to $13.60 \%$. The personalized HbA1c target level was achieved by 398 patients. The overall proportion of patients who had an HbA1c above the target value was 61.66\% [58.70-64.62\%]. The proportions of uncontrolled patients for other outcome indicators ranged from $30.8 \%$ for HDL-C to $87.37 \%$ for eGFR. The proportions of patients with LDL-C and blood pressure above the therapeutic targets were $53.48 \%$ and $54.00 \%$, respectively. (Table 1)

\subsection{Population-based estimation}

The proportions for reaching the target $\mathrm{HbA1c}$ value were calculated in age and gender strata using our survey's data. There was no significant difference between the two genders in achieving the target $\mathrm{HbA} 1 \mathrm{c}$ level. According to the extrapolation from the surveyed sample to the whole adult population of Hungary, the population of T2DM patients in the country consisted of 495,801 [431,514-560,089] adults, and the number of T2DM patients in Hungary with an HbA1c level that was higher than their personalized target was 294,534 [262,391326,678]. (Table 2)

\subsection{Education dependence of indicators}

Detailed results from analyses on education strata specific indicators are summarized in appendix. According to the multivariate models, the higher level (secondary and tertiary) of education was a consequent motivating factor for each process indicator apart from the fasting blood glucose check-up, and the implementation of antihypertensive and anti-dyslipidaemic treatment. This relationship was education level dependent. The utilization of check-ups was more intensive among secondary and much more intensive among tertiary than among primary level educated patients. (Table 3)

HbA1c, blood pressure and LDL-C therapeutic target achievements were not associated with patients' education. The higher level of education was a significant protective factor for fasting blood glucose and HDL-C target achievements. In contrast, total cholesterol and triglyceride control were less likely at goal among patients with higher education. The obesity and the central obesity showed no association with the education. (Table 3) Most of the long-term outcome indicators showed education independency. Ischemic heart diseases and consequently the macrovascular complications were more frequent among highly 
educated patients. The manifestation of microvascular complications was less likely among secondary and the application of insulin treatment among tertiary educated patients. (Table 3)

\section{Discussion}

Our study presents nationwide, representative Hungarian data related to T2DM care among adults from primary care, covering process and outcome indicators, establishing the required baseline data for future follow-up. It describes heterogeneity of care quality in the function of the education, and estimates the number of T2DM patient with uncontrolled $\mathrm{HbA} 1 \mathrm{c}$ status exploiting the opportunities from the representative nature of our study.

\subsection{Main findings}

\subsubsection{Target achievement for intermediate outcome measures}

The proportion of those with an HbA1c value below target is similar in Hungary as in other Central-Eastern European countries. [12] Approximately 22\% achieved the recommended target of the $6.5 \% \mathrm{HbA} 1 \mathrm{c}$ value in the UK. The proportions were $57 \%, 73 \%$, and $46 \%$ in Australia, in New Zealand, and the US, where the recommended target HbA1c values were under $7 \%, 8 \%$, and 7\%, respectively. [29] Using the 7\% cut-off value, recent studies (GUIDANCE and PANORAMA) had 53.6\% and 62.6\% for controlled proportions. Achieving the target in Hungary (38.34\%), seems to be in the midfield of the reference countries. The relative target achievement value (using 2016 Hungarian data as reference) is closest to 1 in case of the Australian data from year 2006. (Figure 2) [30-32] Related to achieving LDL-C target, Hungary (46.52\%) seems to have average proportion of controlled ones. (Australia 52.8\%, EUROACTION 31.8\%). Achievement of the target TC level in Hungary (36.29\%) is slightly worse compared to other references (US 48\%, UK 73\%, and Australia 44\%). The target value achievement is closest to PANORAMA study values (2010). [29]

However, in the respect of blood pressure values the Hungarian achievement seems to be significantly weaker (12.16\%) than the European references (GUIDANCE 19.3\%, PANORAMA 19.7\% EUROACTION 24.1\%). (Figure 2)

\subsubsection{Process indicators versus outcome indicators}


Approximately $83 \%$ of T2DM patients attended annual HbA1c check in the UK, $74 \%$ in Canada, 65\% in Australia, 64\% in New Zealand and 61\% in the US. However, $61 \%$ attended annual ophthalmological examination in the UK, $48 \%$ in Canada, $67 \%$ in the US. [29] Comparing the attendance rates on annual control examinations with these reference data, attendance in Hungary is above the average rate. However, the high quality suggested by these process indicators is not reflected in outcome indicators. This observation reassures that process indicators only, without outcome indicators, could behave as false quality indicators $[18,33]$.

\subsubsection{Socioeconomic gradient}

Although, GP own services (treating hypertension and T2DM, checking fasting blood sugar level) were not related to patient education, the majority of process indicators which require collaboration with secondary care institutions showed strong and education level dependent associations. It was in line with the published results from developed countries [20,21,34]. On the other hand, contrary to the recent publications $[19,21,35]$, the better secondary care related process indicators are not accompanied with better outcomes. This kind of dissociation was observed in Switzerland as well [20]. As it was expected [19], the long-term prognosis seems to be better among patients with higher level of education in Hungary as it is shown by the less frequent insulin requirement and microvascular complications among them. The unexpected association between the higher education and higher occurrence of ischaemic heart disease can be explained by the more intensive health checking practice, which leads to earlier-stage diagnosis of ischaemic heart diseases. Similar bias was reported by other groups also [36]. Because the seriousness of the accompanying disorders was not investigated in our survey, this explanation cannot be supported by data, and needs further investigation.

\subsection{Strengths and limitations}

Our population-based study investigated a representative sample of Hungarian patients with T2DM. Because, the sampling frame was the whole list of patients from participating general medical practices, and the data collection from medical records was retrospective with standardized protocol, GPs could not affect either the sampling or the selection of the clinical data. Data on wide range of socio-demographic and clinical factors were collected making possible the effective control for confounding. The higher-than- $90 \%$ response rate contributed 
to the prevention of selection bias. Because the sample size was comparable with the country level subsamples of GUIDANCE and PANORAMA studies, our conclusions rely on similar statistical power as the country specific findings of those two reference studies have. [37,38] The main validity problem may have been introduced into the study is an overestimation of the quality of care. Since GPs from the GPMSSP are volunteers, it can be assumed that careful GPs are overrepresented in the survey. According to the NIHIFM data the age and sex adjusted relative risk of premature mortality in the investigated group of general medical practices compared to the national reference is 1.01 (not deviated significantly from the Hungarian average risk), this bias cannot be remarkable. Scarce resources allowed us to focus mainly on quality and response rate, however further investigations are planned to expand the indicator set and continue the follow-up.

\subsection{Conclusions}

Our project could establish a cohort of adult T2DM patients with a sample size corresponds to the national subsamples of GUIDANCE and PANORAMA studies. The cohort was described by process and outcome indicators recommended for monitoring practice, making the Hungarian results useful in comparative international analyses, by providing reliable reference data. Because the sample is representative for about 500000 T2DM adults of Hungary, its follow-up can monitor the progress in the quality improvement in the care for the cc. 300000 patients of the country with missed HbA1c target achievement.

According to the process indicators, the typical Hungarian care corresponds to or better than the reference values from developed countries. The quality of the provided services for glycaemic and lipid status control seems to be proper, but the hypertension control needs thorough improvement based on the observed target achievements.

Data on the social inequalities of the key diabetes-related indicators were produced in Hungary. The social gradient in service provision could be demonstrated, but this inequality is not reflected in the key (HbA1c, LDL-C, and blood pressure) intermediate outcome indicators. It seems that the less educated patients reduced access to care provided by secondary care institutions, is not converted into intermediate outcome level handicaps. However, the long term prognosis does be affected by the social inequality, since the proportion of patients requiring insulin therapy, and the prevalence of microvascular complications are significantly increased among less educated patients in Hungary. 


\section{Acknowledgements}

The reported study was carried out in the framework of the "Public Health Focused Model Programme for Organising Primary Care Services Backed by a Virtual Care Service Centre” (SH/8/1). The Model Programme is funded by the Swiss Government via the Swiss Contribution Programme (SH/8/1) in agreement with the Government of Hungary. Additional source of funding was from the grant of Hungarian Academy of Sciences (MTA 11003, 2006TKI227), from IGEN-HUNGARIAN (TÁMOP-4.2.2.AA-11/1/KONV-2012-0031) project which was co-financed by the European Union and the European Social Fund, and from GINOP-2.3.2-15-2016-00005 project which was co-financed by the European Union and the European Regional Development Fund.

GPs participating in the survey: Judit Horváth, Zsuzsanna Szép, Mónika Bányai, Rozália Hutvágner, Zoltán Hajdú, Klára Gyurcsik, László Miliás, Géza Majoros, Judit Kovács, Tímea Szinku, Julianna Kolman, Éva Pardi, Saman Dulana Kothalawala, Tamás Aranyi, Éva Prokaj, Péter Szerze, Endre Koncz, Péter Szerze, Zoltán Singlár, Csaba Kőszegi, Éva Lencsés, Gyula Unger, Ildikó György, András Péter, Attila Valcsák, Munther Qidan, Zoltán Baráth, Sándor Koczok, Gyöngyi Oláh, Magdolna Czipóth, István Bódis, Máté Belák

\section{Statement on conflict of interests}

The authors declare that they have no conflict of interest.

\section{Ethical approval}

The survey was approved by the Ethics Committee of University of Debrecen (TUKEB 48495-2/2014/EKU (475/2014)) and participants gave informed consent.

\section{Declaration of authorship}

Attila Nagy: performed study, analysed data, wrote the paper. Róza Ádány: designed study, performed study, provided professional instruction on the subject, revised the manuscript. Nóra Kovács, Anita Pálinkás, Valéria Sipos, Ferenc Vincze, Gergő Szőllősi, Orsolya Csenteri: data management. János Sándor: designed study, performed study, provided professional instruction on the subject, revised the manuscript. 


\section{References}

[1] IDF Diabetes Atlas, 8th edn. Brussels, Belgium. IDF Diabetes Atlas, 8th edn. 2017. http://www.diabetesatlas.org (accessed September 13, 2017).

[2] Institute for Health Metrics and Evaluation (IHME). GBD Compare Data Visualization 2016.

[3] Vokó Z, Nagyjánosi L, Kaló Z. Direct health care costs of diabetes mellitus in Hungary. Lege Artis Med 2009; 19:775-80.

[4] Kowalski A, Krikorian A, Lerma EV. Diabetic nephropathy for the primary care provider: new understandings on early detection and treatment. Ochsner J 2014;14:36979.

[5] Nagy A, Adany R, Sandor J. Effect of diagnosis-time and initial treatment on the onset of type 2 diabetes mellitus complications: a population-based representative crosssectional study in Hungary. Diabetes Res Clin Pract 2011;94:e65-67. doi:10.1016/j.diabres.2011.08.007.

[6] Marathe PH, Gao HX, Close KL. American Diabetes Association Standards of Medical Care in Diabetes 2017. J Diabetes 2017;9:320-4. doi:10.1111/1753-0407.12524.

[7] Cebolla B, Björnberg A. Euro Consumer Diabetes Index 2008.

[8] Nicolucci A, Greenfield S, Mattke S. Selecting indicators for the quality of diabetes care at the health systems level in OECD countries. Int J Qual Health Care J Int Soc Qual Health Care 2006;18 Suppl 1:26-30. doi:10.1093/intqhe/mzl023.

[9] Felton A-M, Hall M. Diabetes in Europe policy puzzle: the state we are in. Int Diabetes Nurs 2015;12:3-7. doi:10.1179/2057331615Z.0000000007.

[10] Patterson CC, Dahlquist G, Harjutsalo V, Joner G, Feltbower RG, Svensson J, et al. Early mortality in EURODIAB population-based cohorts of type 1 diabetes diagnosed in childhood since 1989. Diabetologia 2007;50:2439-42. doi:10.1007/s00125-007-0824-8.

[11] Soltész G, Madácsy L, Békefi D, Dankó I. Rising incidence of type 1 diabetes in Hungarian children (1978-1987). Hungarian Childhood Diabetes Epidemiology Group. Diabet Med J Br Diabet Assoc 1990;7:111-4.

[12] Andel M, Grzeszczak W, Michalek J, Medvescek M, Norkus A, Rasa I, et al. A multinational, multi-centre, observational, cross-sectional survey assessing diabetes secondary care in Central and Eastern Europe (DEPAC Survey). Diabet Med J Br Diabet Assoc 2008;25:1195-203. doi:10.1111/j.1464-5491.2008.02570.x.

[13] Jermendy G, Nádas J, Szigethy E, Széles G, Nagy A, Hídvégi T, et al. Prevalence rate of diabetes mellitus and impaired fasting glycemia in Hungary: cross-sectional study on nationally representative sample of people aged 20-69 years. Croat Med J 2010;51:1516.

[14] Nagy A, Nagy B, Adany R, Sandor J. Determinants of low referral rates for ophthalmologic examination in people with type 2 diabetes in Hungary. Diabetes Res Clin Pract 2013;102:e29-31. doi:10.1016/j.diabres.2013.09.014.

[15] EUropean Best Information through Regional Outcomes in Diabetes. Http://WwwEubirodEu 2012.

[16] Gaál Z, Gerő L, Hidvégi T, Jermendy G, Kempler P, Winkler G, et al. Clinical Practice Guideline - Diagnosis, antihyperglycaemic treatment and care of patients with diabetes in adulthood. Diabetol Hung 2017;25:3-77.

[17] Lund SS, Vaag AA. Intensive glycemic control and the prevention of cardiovascular events: implications of the ACCORD, ADVANCE, and VA diabetes trials: a position statement of the American Diabetes Association and a scientific statement of the American College of Cardiology Foundation and the American Heart Association: 
response to Skyler et al. Diabetes Care 2009;32:e90-91; author reply e92-93. doi:10.2337/dc09-9030.

[18] Rurik I. Primary care diabetes in Hungary. Prim Care Diabetes 2007;1:177-9. doi:10.1016/j.pcd.2007.07.008.

[19] Bihan H, Laurent S, Sass C, Nguyen G, Huot C, Moulin JJ, et al. Association among individual deprivation, glycemic control, and diabetes complications: the EPICES score. Diabetes Care 2005;28:2680-5.

[20] Flatz A, Casillas A, Stringhini S, Zuercher E, Burnand B, Peytremann-Bridevaux I. Association between education and quality of diabetes care in Switzerland. Int J Gen Med 2015;8:87-92. doi:10.2147/IJGM.S77139.

[21] Hippisley-Cox J, O'Hanlon S, Coupland C. Association of deprivation, ethnicity, and sex with quality indicators for diabetes: population based survey of 53,000 patients in primary care. BMJ 2004;329:1267-9. doi:10.1136/bmj.38279.588125.7C.

[22] Jackson Y, Lozano Becerra JC, Carpentier M. Quality of diabetes care and health insurance coverage: a retrospective study in an outpatient academic public hospital in Switzerland. BMC Health Serv Res 2016;16:540. doi:10.1186/s12913-016-1801-z.

[23] NCD Risk Factor Collaboration (NCD-RisC). Worldwide trends in diabetes since 1980: a pooled analysis of 751 population-based studies with 4.4 million participants. Lancet Lond Engl 2016;387:1513-30. doi:10.1016/S0140-6736(16)00618-8.

[24] Széles G, Vokó Z, Jenei T, Kardos L, Pocsai Z, Bajtay A, et al. A preliminary evaluation of a health monitoring programme in Hungary. Eur J Public Health 2005;15:26-32. doi:10.1093/eurpub/cki107.

[25] National Guideline of Hungarian Diabetes Association 2014.

[26] Ismail-Beigi F, Moghissi E, Tiktin M, Hirsch IB, Inzucchi SE, Genuth S. Individualizing glycemic targets in type 2 diabetes mellitus: implications of recent clinical trials. Ann Intern Med 2011;154:554-9. doi:10.7326/0003-4819-154-8-201104190-00007.

[27] Kósa Z, Széles G, Kardos L, Kósa K, Németh R, Országh S, et al. A comparative health survey of the inhabitants of Roma settlements in Hungary. Am J Public Health 2007;97:853-9. doi:10.2105/AJPH.2005.072173.

[28] Stata Statistical Software: Release 10. College Station, TX: StataCorp LP: StataCorp; 2007.

[29] Si D, Bailie R, Wang Z, Weeramanthri T. Comparison of diabetes management in five countries for general and indigenous populations: an internet-based review. BMC Health Serv Res 2010;10:169. doi:10.1186/1472-6963-10-169.

[30] Kemp TM, Barr ELM, Zimmet PZ, Cameron AJ, Welborn TA, Colagiuri S, et al. Glucose, Lipid, and Blood Pressure Control in Australian Adults With Type 2 Diabetes: The 1999-2000 AusDiab. Diabetes Care 2005;28:1490-2. doi:10.2337/diacare.28.6.1490.

[31] Ofori SN, Kotseva K. Comparison of treatment outcomes in patients with and without diabetes mellitus attending a multidisciplinary cardiovascular prevention programme (a retrospective analysis of the EUROACTION trial). BMC Cardiovasc Disord 2015;15:11. doi:10.1186/s12872-015-0006-4.

[32] Suija K, Kivisto K, Sarria-Santamera A, Kokko S, Liseckiene I, Bredehorst M, et al. Challenges of audit of care on clinical quality indicators for hypertension and type 2 diabetes across four European countries. Fam Pract 2015;32:69-74. doi:10.1093/fampra/cmu078.

[33] Kotseva K, Wood D, De Backer G, De Bacquer D, Pyörälä K, Keil U, et al. Cardiovascular prevention guidelines in daily practice: a comparison of EUROASPIRE I, II, and III surveys in eight European countries. Lancet Lond Engl 2009;373:929-40. doi:10.1016/S0140-6736(09)60330-5. 
[34] Sortsø C, Lauridsen J, Emneus M, Green A, Jensen PB. Socioeconomic inequality of diabetes patients' health care utilization in Denmark. Health Econ Rev 2017;7:21. doi:10.1186/s13561-017-0155-5.

[35] Ziemer DC, Kolm P, Weintraub WS, Vaccarino V, Rhee MK, Twombly JG, et al. Glucose-independent, black-white differences in hemoglobin A1c levels: a crosssectional analysis of 2 studies. Ann Intern Med 2010;152:770-7. doi:10.7326/00034819-152-12-201006150-00004.

[36] Shekelle PG. Socioeconomic inequalities in indicator scores for diabetes: poor quality or poor measures? BMJ 2004;329:1269-70. doi:10.1136/bmj.38285.603692.7C.

[37] de Pablos-Velasco P, Parhofer KG, Bradley C, Eschwège E, Gönder-Frederick L, Maheux P, et al. Current level of glycaemic control and its associated factors in patients with type 2 diabetes across Europe: data from the PANORAMA study. Clin Endocrinol (Oxf) 2014;80:47-56. doi:10.1111/cen.12119.

[38] Stone MA, Charpentier G, Doggen K, Kuss O, Lindblad U, Kellner C, et al. Quality of care of people with type 2 diabetes in eight European countries: findings from the Guideline Adherence to Enhance Care (GUIDANCE) study. Diabetes Care 2013;36:2628-38. doi:10.2337/dc12-1759. 
Figure 1 - Patient selection for survey

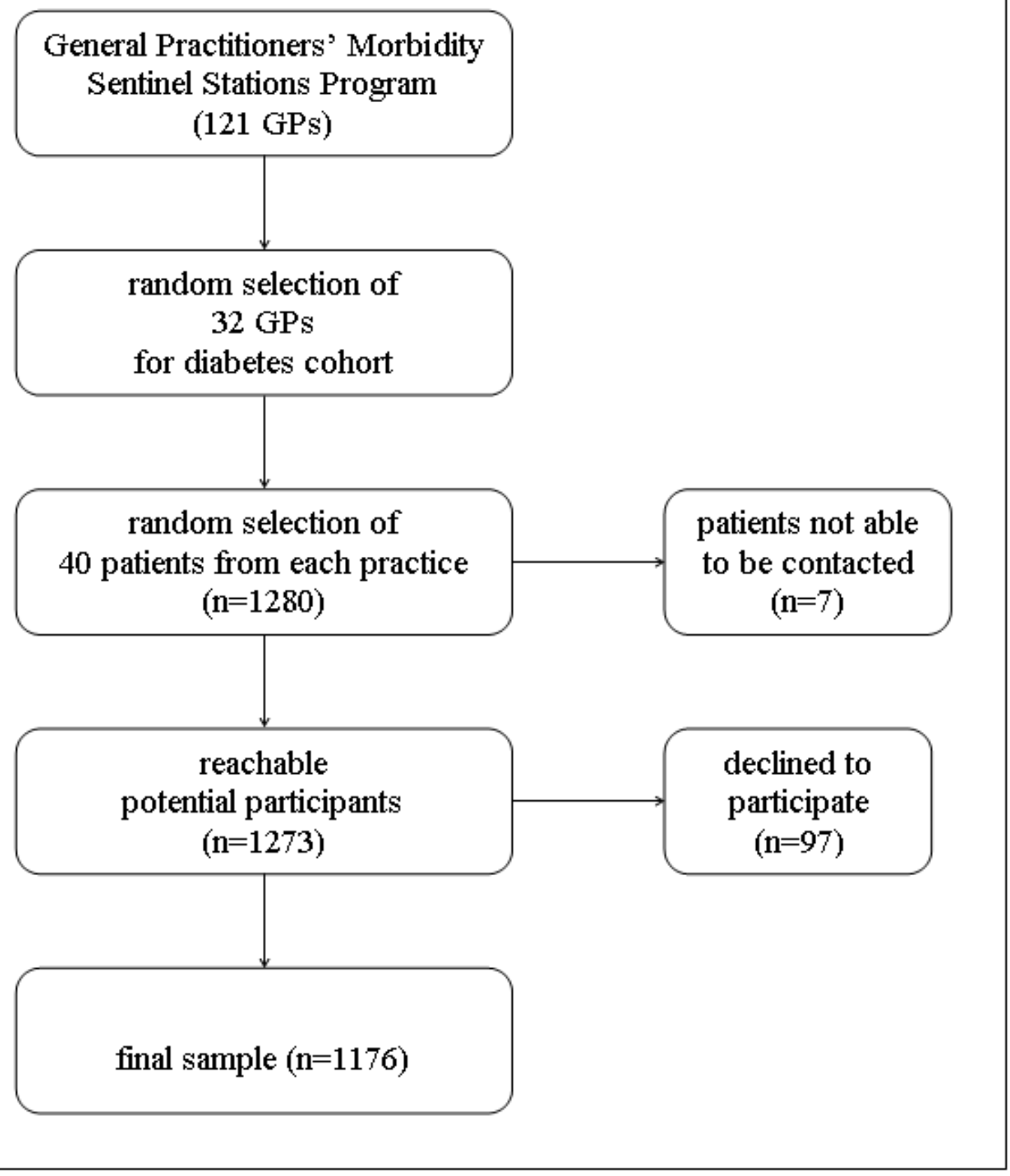


Figure 2 - Relative* HbA1c, blood pressure (BP) and lipid status (LIPID) target value achievements in studies compared to the Hungarian (2016) observations

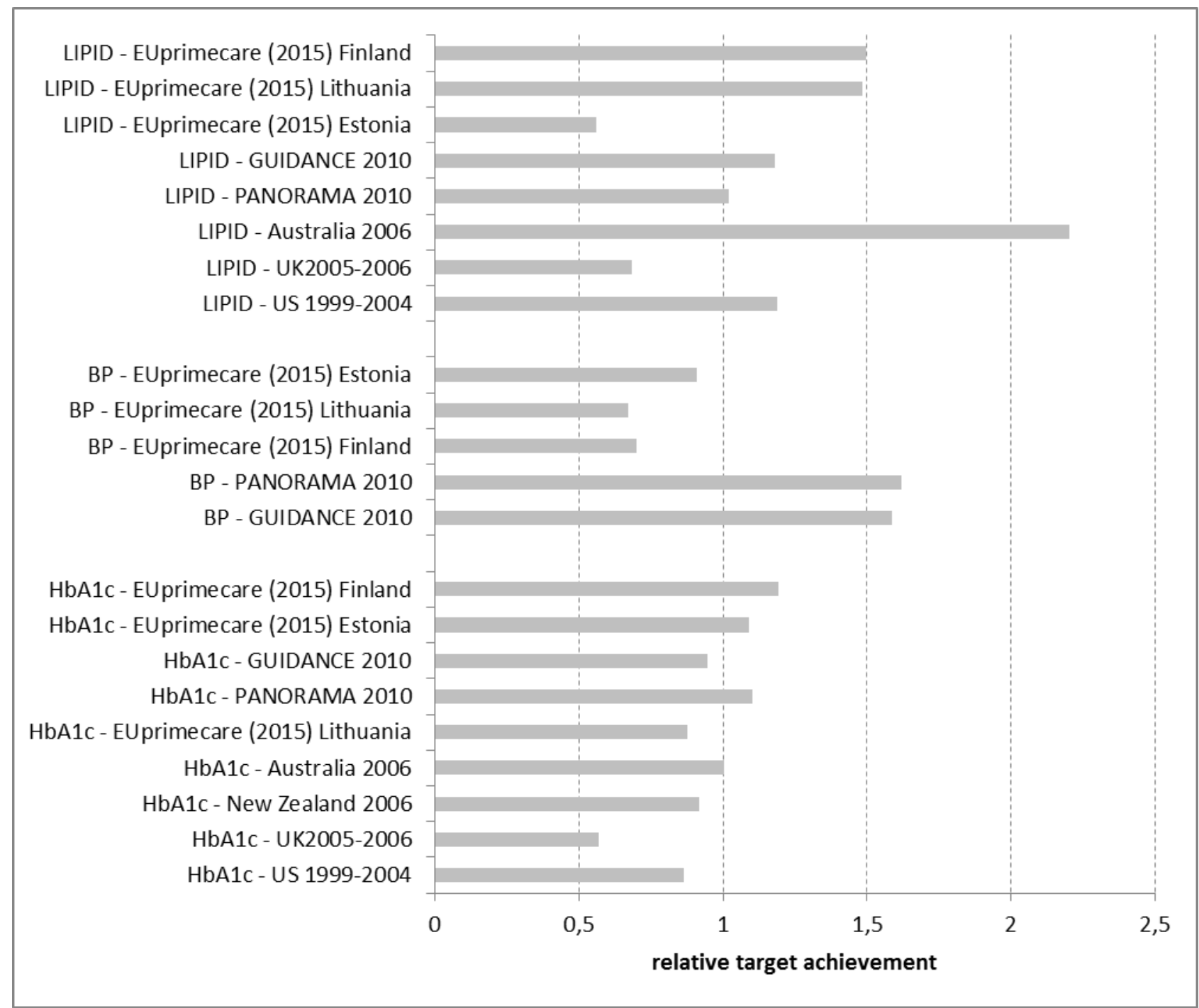

* If a threshold applied in a reference study differed from our investigations' dichotomization value in target achievement ascertainment, then our indicator was recalculated according to the reference study's threshold before the ratio of the reference study and the Hungarian achievements was calculated. 
Table 1 - Descriptive characteristics, proportion of patients investigated within 12 months, and with controlled status in the respect of evaluated indicators

\begin{tabular}{|c|c|c|c|c|c|}
\hline \multirow{2}{*}{ variables } & \multirow{2}{*}{$\mathrm{N}$} & \multirow{2}{*}{ mean $\pm \mathrm{SD}$} & \multirow{2}{*}{$\begin{array}{l}\text { proportion of investigated } \\
\text { patients }\end{array}$} & \multicolumn{2}{|c|}{ uncontrolled among investigated } \\
\hline & & & & number of patients & percentage of patients \\
\hline fasting blood glucose (mmol/l) & 1127 & $8.14 \pm 2.67$ & $95.83 \%$ [94.53-96.9] & 509 & $45.16[42.25-48.07]$ \\
\hline HbA1c (\%) & 1038 & $7.06 \pm 1.35$ & $88.27 \%$ [86.29-90.05] & 640 & $61.66[58.70-64.62]$ \\
\hline $\operatorname{BMI}\left(\mathrm{kg} / \mathrm{m}^{2}\right)$ & 1176 & $\begin{array}{c}30.68 \pm \\
5.13 \\
\end{array}$ & $100 \%$ [99.69-100] & 620 & $52.72[49.87-55.57]$ \\
\hline waist circumference (cm) & 1176 & $\begin{array}{c}106.27 \pm \\
14.44 \\
\end{array}$ & $100 \%$ [99.69-100] & 924 & $78.57[76.23-80.92]$ \\
\hline systolic blood pressure (mmHg) & 1176 & $\begin{array}{c}135.64 \pm \\
13.27 \\
\end{array}$ & $100 \%$ [99.69-100] & \multirow{2}{*}{635} & \multirow{2}{*}{$54.00[51.15-56.85]$} \\
\hline diastolic blood pressure $(\mathrm{mmHg})$ & 1176 & $\begin{array}{c}80.62 \pm \\
8.08\end{array}$ & $100 \%[99.69-100]$ & & \\
\hline eGFR (ml/min/1.73m²) & 942 & $\begin{array}{c}69.76 \pm \\
17.03 \\
\end{array}$ & $80.10 \%$ [7782-82.38] & 823 & $87.37[85.25-89.49]$ \\
\hline $\mathrm{TC}(\mathrm{mmol} / \mathrm{l})$ & 1072 & $5.01 \pm 1.23$ & $91.16 \%$ [89.39-92.72] & 683 & $63.71[60.83-66.59]$ \\
\hline $\mathrm{TG}(\mathrm{mmol} / \mathrm{l})$ & 1069 & $2.01 \pm 1.37$ & $90.9 \%$ [89.11-92.48] & 524 & $49.02[46.02-52.02]$ \\
\hline LDL-C (mmol/l) & 675 & $2.76 \pm 1.04$ & $57.4 \%[54.51-60.25]$ & 361 & $53.48[49.72-57.24]$ \\
\hline HDL-C (mmol/l) & 893 & $\begin{array}{l}1.39 \pm \\
0 . .63 \\
\end{array}$ & $75.94 \%$ [73.39-78.35] & 275 & 30.8 [27.77-33.83] \\
\hline
\end{tabular}


Table 2 - Population-based estimations for the number of diabetes patients reaching target HbA1c level stratified by age and gender

\begin{tabular}{|c|c|c|c|c|c|c|c|c|c|}
\hline & & \multicolumn{4}{|c|}{ male } & \multicolumn{4}{|c|}{ female } \\
\hline & & $18-44$ & $45-64$ & $65-X$ & Total & $18-44$ & $45-64$ & $65-X$ & Total \\
\hline GPMSSP & $\begin{array}{l}\text { T2DM prevalence } \\
\%(\mathrm{n} / \mathrm{N})\end{array}$ & $\begin{array}{c}1.04 \\
(477 / \\
45730) \\
\end{array}$ & $\begin{array}{c}8.65 \\
(2914 / \\
33677) \\
\end{array}$ & $\begin{array}{c}17.07 \\
(2760 / \\
16169) \\
\end{array}$ & $\begin{array}{c}6.44 \\
(6151 / \\
95576)\end{array}$ & $\begin{array}{c}0.85 \\
(371 / \\
43787)\end{array}$ & $\begin{array}{c}6.27 \\
(2292 / \\
36533.5)\end{array}$ & $\begin{array}{c}14.9 \\
(4215 / \\
28289)\end{array}$ & $\begin{array}{c}6.33 \\
(6878 / \\
108609.5)\end{array}$ \\
\hline controlled & $\begin{array}{l}\text { observed in the survey } \\
\%[95 \% \text { confidence } \\
\text { interval }]\end{array}$ & $\begin{array}{c}49.39 \\
{[28.59-70.4]}\end{array}$ & $\begin{array}{c}46.81 \\
{[38.71-55.08]}\end{array}$ & $\begin{array}{c}32.22 \\
{[22.68-43.51]}\end{array}$ & $\begin{array}{c}40.44 \\
{[33.24-48.07]}\end{array}$ & $\begin{array}{c}31.27 \\
{[12.88-58.32]}\end{array}$ & $\begin{array}{c}53.74 \\
{[45.21-62.06]}\end{array}$ & $\begin{array}{c}34.27 \\
{[28.27-40.81]}\end{array}$ & $\begin{array}{c}40.74 \\
{[35.28-46.43]}\end{array}$ \\
\hline $\mathrm{HbA1c}$ & $\begin{array}{l}\text { estimation for Hungary } \\
\text { number of patients [95\% } \\
\text { confidence interval] }\end{array}$ & $\begin{array}{c}9162 \\
{[5032-13292]}\end{array}$ & $\begin{array}{r}51416 \\
{[42343-} \\
60489]\end{array}$ & $\begin{array}{r}33966 \\
{[22856-} \\
45077]\end{array}$ & $\begin{array}{c}94545 \\
{[77076-} \\
112013]\end{array}$ & $\begin{array}{c}4628 \\
{[1054-8202]}\end{array}$ & $\begin{array}{r}47997 \\
{[40403-} \\
55592]\end{array}$ & $\begin{array}{r}54097 \\
{[44145-} \\
64049]\end{array}$ & $\begin{array}{c}106722 \\
{[92047-} \\
121398]\end{array}$ \\
\hline uncontrolled & $\begin{array}{l}\text { observed in the survey } \\
\%[95 \% \text { confidence } \\
\text { interval] }\end{array}$ & $\begin{array}{c}50.61 \\
{[29.6-71.41]}\end{array}$ & $\begin{array}{c}53.19 \\
{[44.92-61.29]}\end{array}$ & $\begin{array}{c}67.78 \\
{[56.49-77.32]}\end{array}$ & $\begin{array}{c}59.56 \\
{[51.93-66.76]}\end{array}$ & $\begin{array}{c}68.73 \\
{[41.68-87.12]}\end{array}$ & $\begin{array}{c}46.26 \\
{[37.94-54.79]}\end{array}$ & $\begin{array}{c}65.73 \\
{[59.19-71.73]}\end{array}$ & $\begin{array}{c}59.26 \\
{[53.57-64.72]}\end{array}$ \\
\hline $\mathrm{HbA1c}$ & $\begin{array}{l}\text { estimation for Hungary } \\
\text { number of patients [95\% } \\
\text { confidence interval] }\end{array}$ & $\begin{array}{c}9389 \\
{[5258-13519]}\end{array}$ & $\begin{array}{r}58428 \\
{[49355-} \\
67501]\end{array}$ & $\begin{array}{r}71450 \\
{[60340-} \\
82561]\end{array}$ & $\begin{array}{c}139267 \\
{[121799-} \\
156736]\end{array}$ & $\begin{array}{c}10173 \\
{[6599-13747]}\end{array}$ & $\begin{array}{r}41317 \\
{[33722-} \\
48911]\end{array}$ & $\begin{array}{l}103778 \\
{[93826-} \\
113730]\end{array}$ & $\begin{array}{c}155267 \\
{[140592-} \\
169942]\end{array}$ \\
\hline
\end{tabular}


Table 3 - Process indicators of type 2 diabetes care (implementation of annual check-ups and application of medication for dyslipidaemia and hypertension), occurrence of uncontrolled status in the respect of intermediate outcome indicators, comorbidities, and insulin treatment requirement by education of patients

\begin{tabular}{|c|c|c|}
\hline \multirow{2}{*}{ Indicators } & \multicolumn{2}{|c|}{ adjusted OR [95\% confidence interval] by education } \\
\hline & Secondary/Primary & Tertiary/Primary \\
\hline \multicolumn{3}{|l|}{ Process indicators: } \\
\hline Ophthalmological check-up* & $1.700 \quad[1.276-2.264]$ & $3.018 \quad[1.941-4.694]$ \\
\hline HbA1c check-up* & $1.573 \quad[1.076-2.299]$ & $4.936 \quad[2.196-11.097]$ \\
\hline Treated dyslipidaemia* & $1.268[0.957-1.680]$ & $1.123[0.754-1.672]$ \\
\hline Treated hypertension* & $1.362[0.789-2.351]$ & $1.034 \quad[0.478-2.238]$ \\
\hline Fasting blood glucose check-up* & $1.221[0.640-2.329]$ & $2.220 \quad[0.728-6.764]$ \\
\hline TC check-up* & $2.281 \quad[1.435-3.626]$ & $5.036 \quad[1.947-13.027]$ \\
\hline TG check-up* & $2.117 \quad[1.343-3.337]$ & $5.271 \quad[2.036-13.647]$ \\
\hline LDL-C check-up* & $1.214[0.928-1.590]$ & $2.127 \quad[1.418-3.191]$ \\
\hline HDL-C check-up* & $1.708 \quad[1.258-2.320]$ & $2.731 \quad[1.642-4.543]$ \\
\hline \multicolumn{3}{|l|}{ Uncontrolled intermediate outcomes: } \\
\hline HbA1c* & $0.714[0.451-1.130]$ & $0.714[0.364-1.400]$ \\
\hline Fasting blood glucose* & $0.998 \quad[0.758-1.315]$ & $0.661 \quad[0.442-0.988]$ \\
\hline BMI* & $0.802[0.611-1.053]$ & $0.801 \quad[0.544-1.181]$ \\
\hline Waist circumference* & $0.932[0.658-1.321]$ & $0.874 \quad[0.546-1.401]$ \\
\hline Blood pressure* & $1.032[0.779-1.367]$ & $0.929[0.618-1.394]$ \\
\hline TC level* & $1.341 \quad[0.999-1.800]$ & $1.662[1.088-2.54]$ \\
\hline TG level* & $1.567 \quad[1.181-2.080]$ & $1.441[0.971-2.141]$ \\
\hline LDL-C level* & $1.158 \quad[0.806-1.665]$ & $1.169[0.722-1.893]$ \\
\hline HDL-C level* ${ }^{*}$ & $0.676 \quad[0.481-0.950]$ & $0.891 \quad[0.556-1.428]$ \\
\hline \multicolumn{3}{|c|}{ Comorbidities and insulin requirement: } \\
\hline Hypertension** & $1.195[0.800-1.784]$ & $1.485 \quad[0.807-2.734]$ \\
\hline Retinopathy** & $0.707 \quad[0.491-1.020]$ & $0.661 \quad[0.380-1.149]$ \\
\hline Stroke** & $1.115 \quad[0.684-1.818]$ & $1.131 \quad[0.579-2.209]$ \\
\hline Myocardial infraction** & $1.452[0.846-2.494]$ & $0.614[0.243-1.554]$ \\
\hline Ischemic heart disease ${ }^{* *}$ & $1.332[0.991-1.790]$ & $1.519[1.005-2.296]$ \\
\hline Nephropathy** & $0.814 \quad[0.556-1.193]$ & $0.857 \quad[0.496-1.479]$ \\
\hline Amputation** & $1.179 \quad[0.262-5.299]$ & $0.736 \quad[0.076-7.158]$ \\
\hline Microvascular complication** & $0.684 \quad[0.506-0.925]$ & $0.685 \quad[0.440-1.064]$ \\
\hline Macrovascular complication** & $1.397 \quad[1.046-1.866]$ & $1.537 \quad[1.022-2.311]$ \\
\hline Insulin treatment $* *$ & $0.773[0.552-1.083]$ & $0.565[0.333-0.960]$ \\
\hline
\end{tabular}

* adjusted for age, sex, duration of diabetes, application of insulin treatment, manifestation of hypertension, retinopathy, stroke, myocardial infraction, ischemic heart disease, nephropathy, amputation by multivariate logistic regression analysis ** adjusted for age, sex, duration of diabetes by multivariate logistic regression analysis 
Appendix 1 - Process indicators of type 2 diabetes care (implementation of annual check-ups and application of medication for dyslipidaemia and hypertension) by education patients

\begin{tabular}{|c|c|c|c|c|c|c|c|c|c|}
\hline \multirow[b]{2}{*}{ Indicators } & \multicolumn{5}{|c|}{ Prevalence [ $95 \%$ confidence interval] by education } & \multicolumn{4}{|c|}{ adjusted OR [95\% confidence interval] by education* } \\
\hline & Primary & Secondary & Tertiary & Total & p-value & $\begin{array}{l}\text { Secondary/Pri } \\
\text { mary }\end{array}$ & p-value & $\begin{array}{l}\text { Tertiary/Prima } \\
\text { ry }\end{array}$ & p-value \\
\hline $\begin{array}{l}\text { Ophthalmological } \\
\text { check-up }\end{array}$ & $\begin{array}{c}58.37 \\
{[53.89-62.84]}\end{array}$ & $\begin{array}{c}65.65 \\
{[61.70-69.59]}\end{array}$ & $\begin{array}{c}76.62 \\
{[69.94-83.31]}\end{array}$ & $\begin{array}{c}64.20 \\
{[61.46-66.94]}\end{array}$ & $<0.001$ & $\begin{array}{c}1.700 \\
{[1.276-2.264]}\end{array}$ & $<0.001$ & $\begin{array}{c}3.018 \\
{[1.941-4.694]}\end{array}$ & $<0.001$ \\
\hline HbA1c check-up & $\begin{array}{c}82.40[78.95- \\
85.86]\end{array}$ & $\begin{array}{c}87.95 \\
{[85.24-90.66]}\end{array}$ & $\begin{array}{c}95.45 \\
{[92.16-98.74]}\end{array}$ & $\begin{array}{c}86.73 \\
{[84.80-88.67]}\end{array}$ & $<0.001$ & $\begin{array}{c}1.573 \\
{[1.076-2.299]}\end{array}$ & 0.019 & $\begin{array}{c}4.936 \\
{[2.196-} \\
11.097] \\
\end{array}$ & $<0.001$ \\
\hline Treated dyslipidaemia & $\begin{array}{c}56.01 \\
{[51.50-60.52]} \\
\end{array}$ & $\begin{array}{c}58.99 \\
{[54.90-63.08]} \\
\end{array}$ & $\begin{array}{c}56.49 \\
{[48.66-64.32]} \\
\end{array}$ & $\begin{array}{c}57.48 \\
{[54.66-60.31]} \\
\end{array}$ & 0.608 & $\begin{array}{c}1.268 \\
{[0.957-1.680]}\end{array}$ & 0.099 & $\begin{array}{c}1.123 \\
{[0.754-1.672]} \\
\end{array}$ & 0.57 \\
\hline Treated hypertension & $\begin{array}{c}87.34 \\
{[84.32-90.36]}\end{array}$ & $\begin{array}{c}86.15 \\
{[83.28-89.02]}\end{array}$ & $\begin{array}{c}87.01 \\
{[81.70-92.32]}\end{array}$ & $\begin{array}{c}86.73 \\
{[84.80-88.67]}\end{array}$ & 0.855 & $\begin{array}{c}1.362 \\
{[0.789-2.351]}\end{array}$ & 0.268 & $\begin{array}{c}1.034 \\
{[0.478-2.238]}\end{array}$ & 0.932 \\
\hline $\begin{array}{l}\text { Fasting blood glucose } \\
\text { check-up }\end{array}$ & $\begin{array}{c}95.71 \\
{[93.87-97.55]}\end{array}$ & $\begin{array}{c}95.50 \\
{[93.78-97.23]}\end{array}$ & $\begin{array}{c}97.40 \\
{[94.89-99.91]}\end{array}$ & $\begin{array}{c}95.83 \\
{[94.69-96.98]}\end{array}$ & 0.599 & $\begin{array}{c}1.221 \\
{[0.640-2.329]}\end{array}$ & 0.545 & $\begin{array}{c}2.220 \\
{[0.728-6.764]}\end{array}$ & 0.161 \\
\hline TC check-up & $\begin{array}{c}86.91 \\
{[83.85-89.97]}\end{array}$ & $\begin{array}{c}93.17 \\
{[91.07-95.26]}\end{array}$ & $\begin{array}{c}96.75 \\
{[93.95-99.55]}\end{array}$ & $\begin{array}{c}91.16 \\
{[89.53-92.78]}\end{array}$ & $<0.001$ & $\begin{array}{c}2.281 \\
{[1.435-3.626]}\end{array}$ & $<0.001$ & $\begin{array}{c}5.036 \\
{[1.947-} \\
13.027]\end{array}$ & 0.001 \\
\hline TG check-up & $\begin{array}{c}86.91 \\
{[83.85-89.97]}\end{array}$ & $\begin{array}{c}92.63 \\
{[90.45-94.80]}\end{array}$ & $\begin{array}{c}96.75 \\
{[93.95-99.55]}\end{array}$ & $\begin{array}{c}90.90 \\
{[89.26-92.55]}\end{array}$ & $<0.001$ & $\begin{array}{c}2.117 \\
{[1.343-3.337]}\end{array}$ & 0.001 & $\begin{array}{c}5.271 \\
{[2.036-} \\
13.647] \\
\end{array}$ & 0.001 \\
\hline LDL-C check-up & $\begin{array}{c}54.72 \\
{[50.20-59.24]} \\
\end{array}$ & $\begin{array}{c}56.29 \\
{[52.17-60.42]} \\
\end{array}$ & $\begin{array}{c}69.48 \\
{[62.21-76.75]} \\
\end{array}$ & $\begin{array}{c}57.40 \\
{[54.57-60.22]} \\
\end{array}$ & 0.004 & $\begin{array}{c}1.214 \\
{[0.928-1.590]} \\
\end{array}$ & 0.158 & $\begin{array}{c}2.127 \\
{[1.418-3.191]} \\
\end{array}$ & $<0.001$ \\
\hline HDL-C check-up & $\begin{array}{c}69.74 \\
{[65.57-73.91]}\end{array}$ & $\begin{array}{c}78.42 \\
{[75.00-81.84]}\end{array}$ & $\begin{array}{c}85.71 \\
{[80.19-91.24]}\end{array}$ & $\begin{array}{c}75.94 \\
{[73.49-78.38]}\end{array}$ & $<0.001$ & $\begin{array}{c}1.708 \\
{[1.258-2.320]}\end{array}$ & 0.001 & $\begin{array}{c}2.731 \\
{[1.642-4.543]}\end{array}$ & $<0.001$ \\
\hline
\end{tabular}

* adjusted for age, sex, duration of diabetes, application of insulin treatment, manifestation of hypertension, retinopathy, stroke, myocardial infraction, ischemic heart disease, nephropathy, amputation by multivariate logistic regression analysis 
Appendix 2 - Occurrence of uncontrolled status in the respect of intermediate outcome indicators among type 2 diabetes patients by education

\begin{tabular}{|c|c|c|c|c|c|c|c|c|c|}
\hline \multirow[b]{2}{*}{ Indicators } & \multicolumn{5}{|c|}{ Prevalence [ $95 \%$ confidence interval] by education } & \multicolumn{4}{|c|}{ adjusted OR [ $95 \%$ confidence interval] by education* } \\
\hline & Primary & Secondary & Tertiary & Total & p-value & $\begin{array}{c}\text { Secondary/Pri } \\
\text { mary }\end{array}$ & p-value & $\begin{array}{c}\text { Tertiary/Prima } \\
\text { ry }\end{array}$ & p-value \\
\hline HbA1c & $\begin{array}{c}64.89 \\
{[60.17-69.60]}\end{array}$ & $\begin{array}{c}59.24 \\
{[54.92-63.55]}\end{array}$ & $\begin{array}{c}61.22 \\
{[53.35-69.10]}\end{array}$ & $\begin{array}{c}61.66 \\
{[58.70-64.61]}\end{array}$ & 0.226 & $\begin{array}{c}0.714 \\
{[0.451-1.130]}\end{array}$ & 0.151 & $\begin{array}{c}0.714 \\
{[0.364-1.400]}\end{array}$ & 0.327 \\
\hline Fasting blood glucose & $\begin{array}{c}45.29 \\
{[40.67-49.91]}\end{array}$ & $\begin{array}{c}47.46 \\
{[43.21-51.70]}\end{array}$ & $\begin{array}{c}36.67 \\
{[28.95-44.38]}\end{array}$ & $\begin{array}{c}45.16 \\
{[42.26-48.07]}\end{array}$ & 0.064 & $\begin{array}{c}0.998 \\
{[0.758-1.315]}\end{array}$ & 0.991 & $\begin{array}{c}0.661 \\
{[0.442-0.988]}\end{array}$ & 0.044 \\
\hline BMI & $\begin{array}{c}52.36 \\
{[47.83-56.90]}\end{array}$ & $\begin{array}{c}53.24 \\
{[49.09-57.38]}\end{array}$ & $\begin{array}{c}51.95 \\
{[44.06-59.84]}\end{array}$ & $\begin{array}{c}52.72 \\
{[49.87-55.57]}\end{array}$ & 0.943 & $\begin{array}{c}0.802 \\
{[0.611-1.053]}\end{array}$ & 0.112 & $\begin{array}{c}0.801 \\
{[0.544-1.181]}\end{array}$ & 0.263 \\
\hline Waist circumference & $\begin{array}{c}82.40 \\
{[78.95-85.86]} \\
\end{array}$ & $\begin{array}{c}76.80 \\
{[73.29-80.31]} \\
\end{array}$ & $\begin{array}{c}73.38 \\
{[66.40-80.36]}\end{array}$ & $\begin{array}{c}78.57 \\
{[76.23-80.92]} \\
\end{array}$ & 0.023 & $\begin{array}{c}0.932 \\
{[0.658-1.321]}\end{array}$ & 0.693 & $\begin{array}{c}0.874 \\
{[0.546-1.401]} \\
\end{array}$ & 0.576 \\
\hline Blood pressure & $\begin{array}{c}31.97 \\
{[27.74-36.21]}\end{array}$ & $\begin{array}{c}35.43 \\
{[31.46-39.41]}\end{array}$ & $\begin{array}{c}32.47 \\
{[25.07-39.86]}\end{array}$ & $\begin{array}{c}33.67 \\
{[30.97-36.37]}\end{array}$ & 0.478 & $\begin{array}{c}1.032 \\
{[0.779-1.367]}\end{array}$ & 0.828 & $\begin{array}{c}0.929 \\
{[0.618-1.394]}\end{array}$ & 0.721 \\
\hline TC level & $\begin{array}{c}59.26 \\
{[54.47-64.04]}\end{array}$ & $\begin{array}{c}65.64 \\
{[61.55-69.73]}\end{array}$ & $\begin{array}{c}69.13 \\
{[61.71-76.55]}\end{array}$ & $\begin{array}{c}63.71 \\
{[60.83-66.59]}\end{array}$ & 0.045 & $\begin{array}{c}1.341 \\
{[0.999-1.800]}\end{array}$ & 0.051 & $\begin{array}{c}1.662 \\
{[1.088-2.54]}\end{array}$ & 0.019 \\
\hline TG level & $\begin{array}{c}41.73 \\
{[36.93-46.53]}\end{array}$ & $\begin{array}{c}54.17 \\
{[49.87-58.48]}\end{array}$ & $\begin{array}{c}51.01 \\
{[42.98-59.03]} \\
\end{array}$ & $\begin{array}{c}49.02 \\
{[46.02-52.01]} \\
\end{array}$ & 0.001 & $\begin{array}{c}1.567 \\
{[1.181-2.080]} \\
\end{array}$ & 0.002 & $\begin{array}{c}1.441 \\
{[0.971-2.141]}\end{array}$ & 0.07 \\
\hline LDL-C level & $\begin{array}{c}51.37 \\
{[45.24-57.51]}\end{array}$ & $\begin{array}{c}54.95 \\
{[49.44-60.46]}\end{array}$ & $\begin{array}{c}54.21 \\
{[44.77-63.65]}\end{array}$ & $\begin{array}{c}53.48 \\
{[49.72-57.24]}\end{array}$ & 0.696 & $\begin{array}{c}1.158 \\
{[0.806-1.665]}\end{array}$ & 0.428 & $\begin{array}{c}1.169 \\
{[0.722-1.893]}\end{array}$ & 0.525 \\
\hline HDL-C level & $\begin{array}{c}37.85 \\
{[32.57-43.12]} \\
\end{array}$ & $\begin{array}{c}26.15 \\
{[22.02-30.27]} \\
\end{array}$ & $\begin{array}{c}28.79 \\
{[21.06-36.51]} \\
\end{array}$ & $\begin{array}{c}30.80 \\
{[27.77-33.82]} \\
\end{array}$ & 0.002 & $\begin{array}{c}0.676 \\
{[0.481-0.950]} \\
\end{array}$ & 0.024 & $\begin{array}{c}0.891 \\
{[0.556-1.428]} \\
\end{array}$ & 0.632 \\
\hline
\end{tabular}

* adjusted for age, sex, duration of diabetes, application of insulin treatment, manifestation of hypertension, retinopathy, stroke, myocardial infraction, ischemic heart disease, nephropathy, amputation by multivariate logistic regression analysis 
Appendix 3 - Comorbidities, complications, and insulin treatment requirement by education among type 2 diabetes patients

\begin{tabular}{|c|c|c|c|c|c|c|c|c|c|}
\hline \multirow[b]{2}{*}{ Indicators } & \multicolumn{5}{|c|}{ Prevalence [ $95 \%$ confidence interval] by education } & \multicolumn{4}{|c|}{ adjusted OR [ $95 \%$ confidence interval] by education* } \\
\hline & Primary & Secondary & Tertiary & Total & p-value & $\begin{array}{c}\text { Secondary/Pri } \\
\text { mary }\end{array}$ & p-value & $\begin{array}{c}\text { Tertiary/Prima } \\
\text { ry }\end{array}$ & p-value \\
\hline Hypertension & $\begin{array}{c}88.41 \\
{[85.51-91.32]} \\
\end{array}$ & $\begin{array}{c}85.79 \\
{[82.89-88.69]} \\
\end{array}$ & $\begin{array}{c}88.96 \\
{[84.01-93.91]} \\
\end{array}$ & $\begin{array}{c}87.24 \\
{[85.34-89.15]} \\
\end{array}$ & 0.363 & $\begin{array}{c}1.195 \\
{[0.800-1.784]} \\
\end{array}$ & 0.384 & $\begin{array}{c}1.485 \\
{[0.807-2.734]} \\
\end{array}$ & 0.204 \\
\hline Retinopathy & $\begin{array}{c}19.31 \\
{[15.73-22.90]} \\
\end{array}$ & $\begin{array}{c}12.77 \\
{[10.00-15.54]} \\
\end{array}$ & $\begin{array}{c}12.34 \\
{[7.14-17.53]} \\
\end{array}$ & $\begin{array}{c}15.31 \\
{[13.25-17.36]} \\
\end{array}$ & 0.008 & $\begin{array}{c}0.707 \\
{[0.491-1.020]} \\
\end{array}$ & 0.064 & $\begin{array}{c}0.661 \\
{[0.380-1.149]} \\
\end{array}$ & 0.142 \\
\hline Stroke & $\begin{array}{c}8.37 \\
{[5.85-10.88]}\end{array}$ & $\begin{array}{c}7.73 \\
{[5.51-9.95]}\end{array}$ & $\begin{array}{c}9.09 \\
{[4.55-13.63]}\end{array}$ & $\begin{array}{c}8.16 \\
{[6.60-9.73]}\end{array}$ & 0.833 & $\begin{array}{c}1.115 \\
{[0.684-1.818]}\end{array}$ & 0.662 & $\begin{array}{c}1.131 \\
{[0.579-2.209]}\end{array}$ & 0.719 \\
\hline Myocardial infraction & $\begin{array}{c}5.58 \\
{[3.50-7.66]} \\
\end{array}$ & $\begin{array}{c}7.73 \\
{[5.51-9.95]} \\
\end{array}$ & $\begin{array}{c}3.90 \\
{[0.84-6.95]} \\
\end{array}$ & $\begin{array}{c}6.38 \\
{[4.98-7.77]} \\
\end{array}$ & 0.152 & $\begin{array}{c}1.452 \\
{[0.846-2.494]}\end{array}$ & 0.176 & $\begin{array}{c}0.614 \\
{[0.243-1.554]} \\
\end{array}$ & 0.303 \\
\hline Ischemic heart disease & $\begin{array}{c}33.91 \\
{[29.61-38.20]} \\
\end{array}$ & $\begin{array}{c}31.29 \\
{[27.44-35.15]}\end{array}$ & $\begin{array}{c}37.66 \\
{[30.01-45.32]} \\
\end{array}$ & $\begin{array}{c}33.16 \\
{[30.47-35.85]} \\
\end{array}$ & 0.299 & $\begin{array}{c}1.332 \\
{[0.991-1.790]}\end{array}$ & 0.057 & $\begin{array}{c}1.519 \\
{[1.005-2.296]}\end{array}$ & 0.047 \\
\hline Nephropathy & $\begin{array}{c}21.03 \\
{[17.33-24.73]} \\
\end{array}$ & $\begin{array}{c}11.33 \\
{[8.70-13.97]} \\
\end{array}$ & $\begin{array}{c}14.29 \\
{[8.76-19.81]} \\
\end{array}$ & $\begin{array}{c}15.56 \\
{[13.49-17.63]} \\
\end{array}$ & $<0.001$ & $\begin{array}{c}0.814 \\
{[0.556-1.193]} \\
\end{array}$ & 0.291 & $\begin{array}{c}0.857 \\
{[0.496-1.479]} \\
\end{array}$ & 0.579 \\
\hline Amputation & $\begin{array}{c}0.86 \\
{[0.23-2.18]}\end{array}$ & $\begin{array}{c}0.72 \\
{[0.20-1.83]}\end{array}$ & $\begin{array}{c}0.65 \\
{[0.02-3.56]}\end{array}$ & $\begin{array}{c}0.77 \\
{[0.35-1.45]}\end{array}$ & 1.000 & $\begin{array}{c}1.179 \\
{[0.262-5.299]}\end{array}$ & 0.83 & $\begin{array}{c}0.736 \\
{[0.076-7.158]}\end{array}$ & 0.792 \\
\hline $\begin{array}{l}\text { Microvascular } \\
\text { complication }\end{array}$ & $\begin{array}{c}37.12 \\
{[32.74-41.51]} \\
\end{array}$ & $\begin{array}{c}22.30 \\
{[18.84-25.76]} \\
\end{array}$ & $\begin{array}{c}24.68 \\
{[17.87-31.48]} \\
\end{array}$ & $\begin{array}{c}28.49 \\
{[25.91-31.07]} \\
\end{array}$ & $<0.001$ & $\begin{array}{c}0.684 \\
{[0.506-0.925]} \\
\end{array}$ & 0.014 & $\begin{array}{c}0.685 \\
{[0.440-1.064]} \\
\end{array}$ & 0.092 \\
\hline $\begin{array}{l}\text { Macrovascular } \\
\text { complication }\end{array}$ & $\begin{array}{c}38.41 \\
{[34.00-42.83]} \\
\end{array}$ & $\begin{array}{c}36.69 \\
{[32.68-40.70]} \\
\end{array}$ & $\begin{array}{c}42.86 \\
{[35.04-50.67]} \\
\end{array}$ & $\begin{array}{c}38.18 \\
{[35.4-40.96]} \\
\end{array}$ & 0.378 & $\begin{array}{c}1.397 \\
{[1.046-1.866]}\end{array}$ & 0.024 & $\begin{array}{c}1.537 \\
{[1.022-2.311]} \\
\end{array}$ & 0.039 \\
\hline Insulin treatment & $\begin{array}{c}22.53 \\
{[18.74-26.33]}\end{array}$ & $\begin{array}{c}19.42 \\
{[16.14-22.71]}\end{array}$ & $\begin{array}{c}14.94 \\
{[9.31-20.56]}\end{array}$ & $\begin{array}{c}20.07 \\
{[17.78-22.36]}\end{array}$ & 0.111 & $\begin{array}{c}0.773 \\
{[0.552-1.083]}\end{array}$ & 0.135 & $\begin{array}{c}0.565 \\
{[0.333-0.960]}\end{array}$ & 0.035 \\
\hline
\end{tabular}

$*$ adjusted for age, sex, duration of diabetes by multivariate logistic regression analysis 